\title{
A biblioteca escolar: leitura e transformação
}

\author{
The school library: reading and transformation
}

\begin{abstract}
Marcela Lopes Mendonça Coelho de Amorim
Graduada em Serviço Social e Biblioteconomia pela Universidade Federal do Espírito Santo. Atua como bibliotecária em biblioteca escolar há 10 anos. Trabalha há sete anos na Biblioteca da EMEF Aristóbulo Barbosa Leão em Vitória/ES.

E-mail: marcela_lmca@hotmail.com
\end{abstract}

\section{Resumo}

Aborda conceitos ligados à função educativa da biblioteca escolar e à importância do incentivo à leitura. Descreve as atividades realizadas pela bibliotecária na biblioteca da Escola Municipal de Ensino Fundamental Aristóbulo Barbosa Leão, localizada em Vitória, Espírito Santo, a partir da leitura de textos de literatura infantil. Relata ações de incentivo à leitura, deflagradas pela apresentação de diferentes obras literárias, envolvendo música, artes, escrita e contação de histórias, enfatizando a imaginação, a ludicidade, e destacando aspectos culturais os mais diversos e o desenvolvimento da cidadania.

Palavras-chave: Biblioteca escolar. Bibliotecário escolar. Escola pública. Incentivo à leitura. Música na biblioteca.

\begin{abstract}
Discusses concepts related to the educational function of the school library and the importance of encouraging reading. Describes the activities performed by the librarian in the library of the Municipal School of Basic Education Aristobulus Barbosa Leão, in Vitória, Espírito Santo, Brazil, based on children's literature. Reports actions to encourage reading, triggered by the presentation of various literary works, involving music, arts, writing and storytelling, emphasizing imagination, playfulness, and highlighting various cultural aspects and the development of citizenship.
\end{abstract}

Keywords: School library. School librarian. Promotion of reading. Music in the library

\section{Introdução}

A Escola Municipal de Ensino Fundamental Aristóbulo Barbosa Leão, ou ABL, como é chamada, é uma escola da Rede Municipal de Ensino de Vitória, ES, situada em um bairro de classe média da cidade. No entanto, muitos dos alunos, residentes em outros bairros das cercanias, são oriundos de famílias carentes e de comunidades marcadas pela violência. É uma das maiores escolas de Vitória e tem atualmente cerca de 800 alunos divididos em três turnos. São 29 turmas nos turnos matutino e vespertino, além da EJA que funciona no período noturno. A biblioteca tem um espaço pequeno, comporta cerca de 30 alunos assentados e possui um acervo de cerca de 12 mil exemplares de várias áreas do conhecimento, com destaque para as seções de literatura infantil e juvenil. 


\section{Conceitos e teorias que embasaram os projetos/atividades relatados}

Na porta da biblioteca do ABL há um painel com um acróstico elaborado de acordo com o que foi aprendido, ensinado e vivido ao longo desses 10 anos trabalhando como bibliotecária escolar (FIG. 1):

SaBer,

Imaginação,

Brincadeira,

Leitura,

MúsIca,

POesia,

CulTura,

$\operatorname{Art} \mathbf{E}$,

Cidadania,

InformAção.

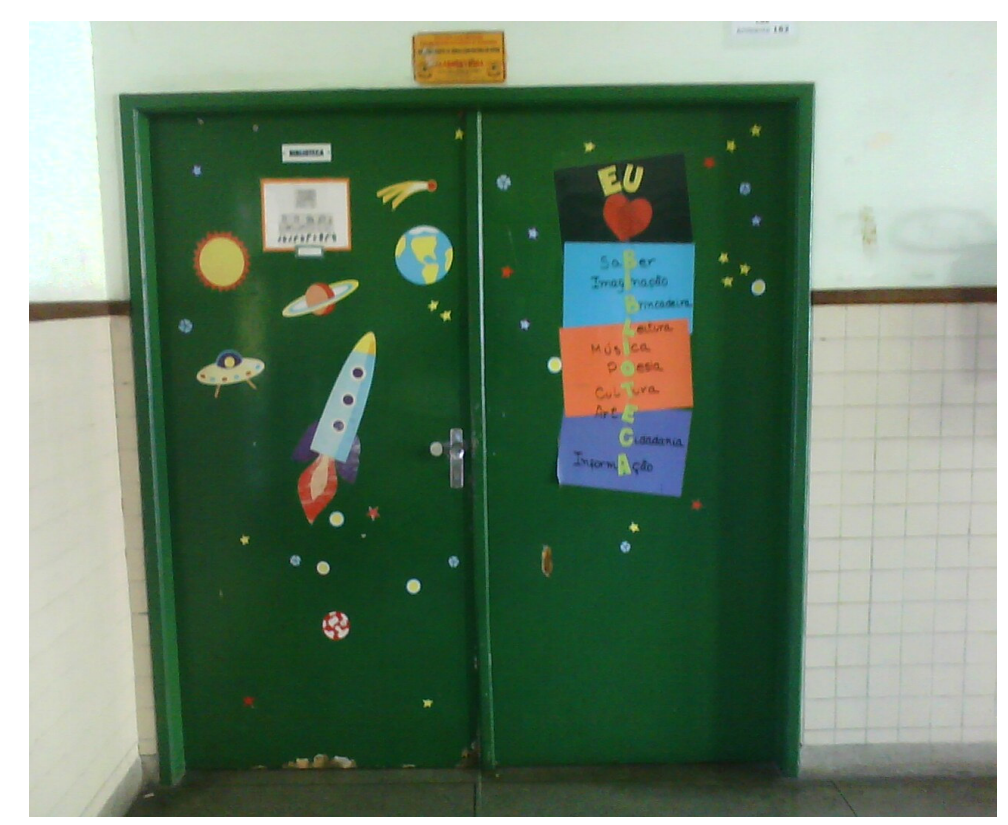

FIGURA 1

Certamente, essas são as palavras-chave evidenciadas no trabalho realizado na biblioteca do ABL. Ao buscar os conceitos e teorias, percebeu-se que algumas das palavras do acróstico aparecem em alguns pontos do Manifesto IFLA/UNESCO para a Biblioteca Escolar (IFLA, 2000, p. 1), por exemplo, "imaginação" aparece ligada à importância e participação da 
biblioteca escolar na aprendizagem ao afirmar que "[...] a biblioteca escolar habilita os estudantes para a aprendizagem ao longo da vida e desenvolve a imaginação, preparando-os para viver como cidadãos responsáveis". Entre os objetivos da biblioteca escolar apresentados pelo Manifesto, a imaginação também aparece ao destacar-se a importância de se “[...] oferecer oportunidades de vivências destinadas à produção e uso da informação voltada ao conhecimento, à compreensão, imaginação e ao entretenimento".

A palavra "leitura" aparece também na afirmação de que "[...] a biblioteca escolar é essencial a qualquer tipo de estratégia de longo prazo no que respeita a competências à leitura e escrita, à educação e à informação e ao desenvolvimento econômico, social e cultural" (IFLA, 2000, p. 2). A leitura é o início de todas as atividades realizadas na biblioteca do ABL.

A "cultura" aparece também no objetivo de se "[...] organizar atividades que incentivem a tomada de consciência cultural e social, bem como de sensibilidade" (IFLA, 2000, p. 3).

O documento Diretrizes IFLA/UNESCO para a Biblioteca Escolar apresenta inclusive um tópico dedicado à função cultural da biblioteca escolar, que permite que ela seja usada como um ambiente estético, cultural e estimulante, através de materiais variados e eventos especiais protagonizados não só por elementos externos (exposições, visitas de autores, etc.), mas também por alunos que podem

[...] produzir atuações inspiradas na literatura para pais e para outros alunos, e o bibliotecário pode organizar leituras em voz alta e atividades de conto de histórias para os mais novos. O bibliotecário deve ainda estimular o interesse pela leitura e organizar programas de promoção da leitura que desenvolvam o gosto pela literatura.

As atividades que se propõem a encorajar a leitura envolvem aspectos culturais, bem como de aprendizagem. Existe uma ligação direta entre o nível de leitura e os resultados da aprendizagem (IFLA, 2006, p. 18).

A função cultural da biblioteca deve ser exercitada com atividades que vão desde a contação de histórias, poesias musicadas, expressões artísticas de desenho, pintura, colagem, apresentações para toda a escola entre outras.

A "cidadania" também é apontada entre os objetivos ligados à liberdade intelectual e ao acesso à informação, pensa-se que "[...] são pontos fundamentais à formação de cidadania responsável e ao exercício da democracia” (IFLA, 2000, p. 3). Essas palavras resumem uma atuação da biblioteca escolar voltada para o aluno e destaca a função educativa do bibliotecário, que, segundo afirmação do documento Diretrizes ILFA/UNESCO para a 
Biblioteca Escolar "[...] deve criar um ambiente para o lazer e a aprendizagem que seja atrativo, acolhedor e acessível a todos sem medo e sem preconceitos" (IFLA, 2006, p. 12, grifo nosso). Refletindo sobre essa afirmação, pensa-se que a "coragem", ao que me parece, precisa ser uma característica do bibliotecário. Segundo Campello (2009, p. 18), “o bibliotecário brasileiro precisa se preparar para enfrentar desafios, se quiser contribuir com suas competências específicas para a formação das pessoas". É preciso realmente de muita coragem para enfrentar os tantos desafios existentes, como, por exemplo, para quebrar o silêncio da biblioteca! É preciso fazer um pouco de "barulho" para que o bibliotecário consiga exercer o seu "[...] papel fundamental [que] é contribuir para a missão e para os objetivos da escola" (IFLA, 2006, p. 11).

O bibliotecário precisa ir ao encontro do aluno para atender suas necessidades de informação, educação, cultura, lazer e demais demandas que o mesmo tiver em relação à biblioteca. O seu conhecimento técnico deve estar aliado à praticidade, pois os acervos precisam estar acessíveis a todos na escola. Os alunos devem ser conquistados, cativados. Cabe a ele compreender as crianças, aguçar nelas a curiosidade, a fim de criar um ambiente atrativo e acolhedor, usando a criatividade nos projetos e incentivando a leitura, sendo mais próximo e comunicativo, motivando os alunos a ler e a frequentar a biblioteca.

Essas afirmativas apontam para a função educativa do bibliotecário que se concentra principalmente

[...] no sentido de auxiliar a comunidade escolar na utilização correta das fontes de informação, dando um embasamento para que o educando saiba usufruir esses conhecimentos, também fora do ambiente escolar. Ele ensina a socialização, através do compartilhamento de informações, de utilização de materiais e ambientes coletivos, preparando assim o educando no desenvolvimento social e cultural (CORREA et al, 2002, p. 03).

É fundamental, para tanto, compreendermos que “[...] a biblioteca escolar serve de modelo para crianças e jovens utilizarem e usufruírem outros espaços informacionais semelhantes ao longo de sua vida" (CAMPELLO, 2009, p. 28).

Segundo as Diretrizes (IFLA, 2006, p. 18), os alunos são o principal público-alvo da biblioteca escolar e podem usar a biblioteca para os mais diversos propósitos, que deve ser usada como um local de “[...] aprendizagem aberto, gratuito, livre e não ameaçador, onde podem desenvolver trabalhos de todos os tipos, individualmente ou em grupo".

Todas estas questões nos levam a confirmar que a biblioteca escolar cumpre um importante papel, atuando como um espaço privilegiando de transformação, "um lugar 
cativante, acolhedor, cheio de vida... mostrando aos leitores que livros podem e devem fazer parte do seu universo" (FRAGOSO, 1994 apud NEVES, 2004, p. 222).

Nóbrega (apud ANJOS, 2009, p.12) enfatiza que a face educadora da biblioteca transparece quando esta não se apresenta "[...] contemplativa ou complacente, mas 'mexedora' do interior do usuário. Transformadora'.

Nesta perspectiva, destaca-se sua ação como agente importantíssimo no incentivo ao hábito de leitura que é fundamental "[...] para que o seu usuário possa usufruir dos benefícios do acesso à informação, seja para o estudo, o ensino, o trabalho, a arte, o lazer ou a diversão" (NEVES, 2004, p.223).

Uma infinidade de estratégias pode ser utilizada para despertar no leitor o desejo de ler, como as realizadas no ABL e muitíssimas outras, já que o livro e a leitura oferecem infinitas possibilidades. A biblioteca escolar oferece condições para o desenvolvimento da leitura e da escrita, principalmente se for alvo de um planejamento conjunto entre professores e bibliotecários que preveja uma integração biblioteca/sala de aula. Nesse sentido, Campello (2010) destaca que a integração e a cooperação entre bibliotecários, professores, pedagogos e toda a equipe da escola torna-se imprescindível para que nesse processo o profissional da biblioteca possa reconhecer-se e ao mesmo tempo ser reconhecido como catalizador/protagonista dessa colaboração, participando de ações de relacionamento não apenas individualmente com os professores, mas buscando, em meio aos sujeitos praticantes, promover uma cultura de colaboração na escola, e tornando-se ainda um importante orientador na elucidação de questões sobre a natureza do ensino-aprendizagem na biblioteca escolar, ambiente permeado por abundância informacional.

\section{Projetos e atividades}

$\mathrm{O}$ trabalho de incentivo à leitura, realizado no $\mathrm{ABL}$, envolve mais diretamente os alunos de $1^{\circ}$ ao $5^{\circ}$ ano, que quinzenalmente vêm à biblioteca e participam de um momento de atividades, que inclui música, poesia, artes plásticas, "contação" de histórias, leitura, escrita e muitas outras atividades, buscando tornar a biblioteca escolar um espaço vivo e agradável. O trabalho, como um todo, tem como objetivo principal o incentivo à leitura de várias maneiras, como diz Ricardo Azevedo (1998, p. 41) em seu poema Aula de leitura, do livro Dezenove Poemas Desengonçados: 
Aula de leitura

A leitura é muito mais do que decifrar palavras;

Quem quiser parar pra ver pode até se surpreender:

vai ler nas folhas do chão, se é outono ou se é verão;

nas ondas soltas no mar, se é hora de navegar;

e no jeito da pessoa, se trabalha ou se é à-toa;

na cara do lutador, quando está sentindo dor;

vai ler na casa de alguém o gosto que o dono tem;

e no pelo do cachorro, se é melhor gritar socorro;

e na cinza da fumaça, o tamanho da desgraça;

e no tom que sopra o vento se corre o barco ou vai lento;

e também na cor da fruta, e no cheiro da comida,

e no ronco do motor, e nos dentes do cavalo, e na pele da pessoa, e no brilho do sorriso, vai ler nas nuvens do céu, vai ler na palma da mão,

vai ler até nas estrelas e no som do coração.

Uma arte que dá medo é a de ler um olhar, pois os olhos têm segredos difíceis de decifrar.

O primeiro verso é apenas um empurrão para a leitura do mundo. No restante do 
poema são descritas uma série de coisas que "lemos" na natureza, nas pessoas. Desde folhas no chão para ler a estação do ano até a as estrelas e o som do coração. É um poema que dá margem a diversas interpretações e foi usado em um trabalho muito interessante realizado com os alunos das séries iniciais do ABL. É sempre muito proveitoso conversar sobre esse poema com os alunos, citando como exemplo a "leitura" que fazem do mar, da natureza, dos olhos, do som do coração. E assim acontece com todos os versos: todos tem algum exemplo de experiência sobre a leitura do mundo. Após a leitura, os alunos são estimulados a interpretar cada verso por meio de textos e desenhos. Nessa atividade, os alunos experimentam um tipo de leitura de mundo que ultrapassa o próprio código escrito. A ênfase nessa leitura mais ampla permeia todo o trabalho realizado na biblioteca e tem trazido resultados muito bons para todos na escola. Os desenhos e textos formaram um livro ilustrado sobre o poema (FIG. 2, 3 e 4).

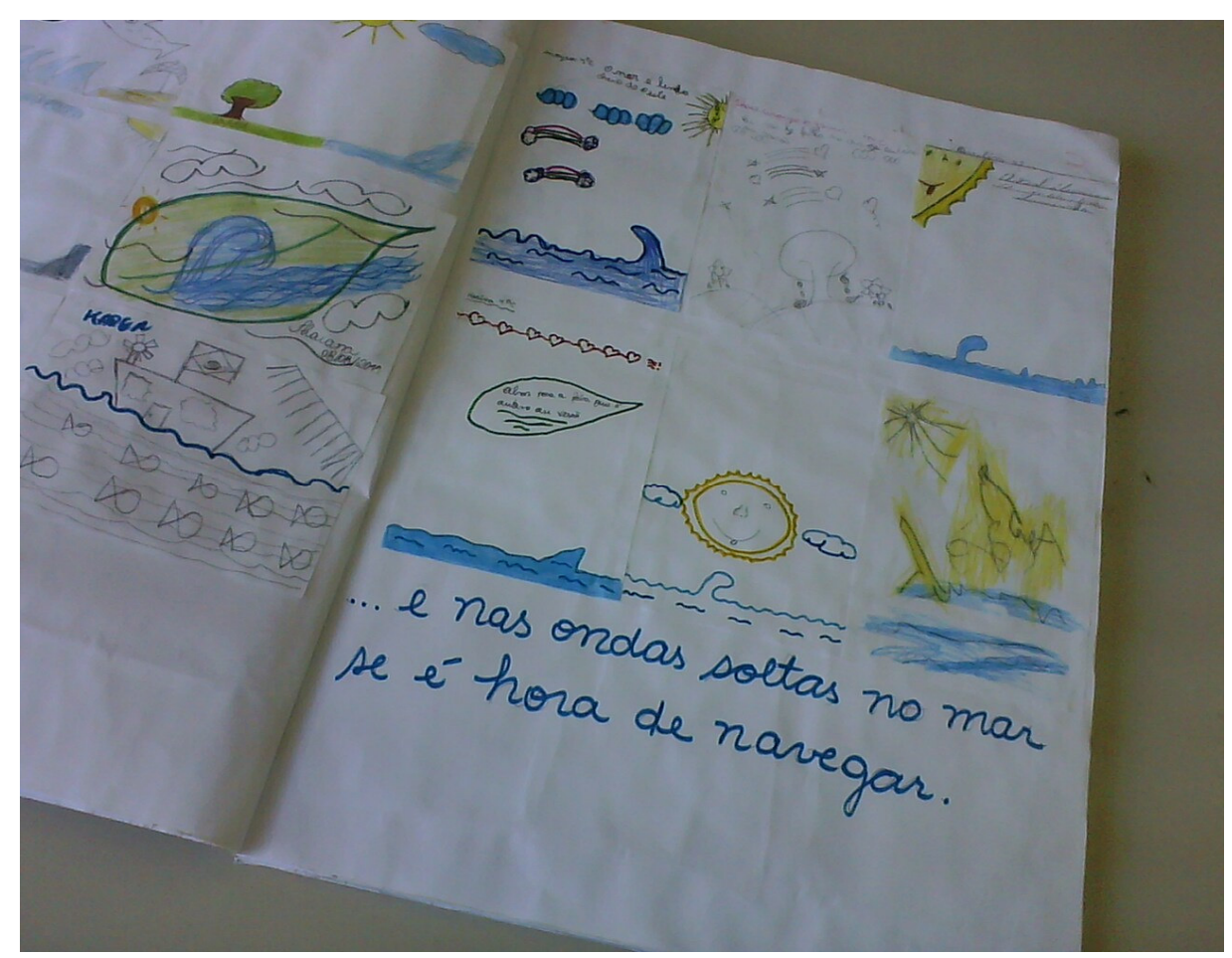

FIGURA 2 


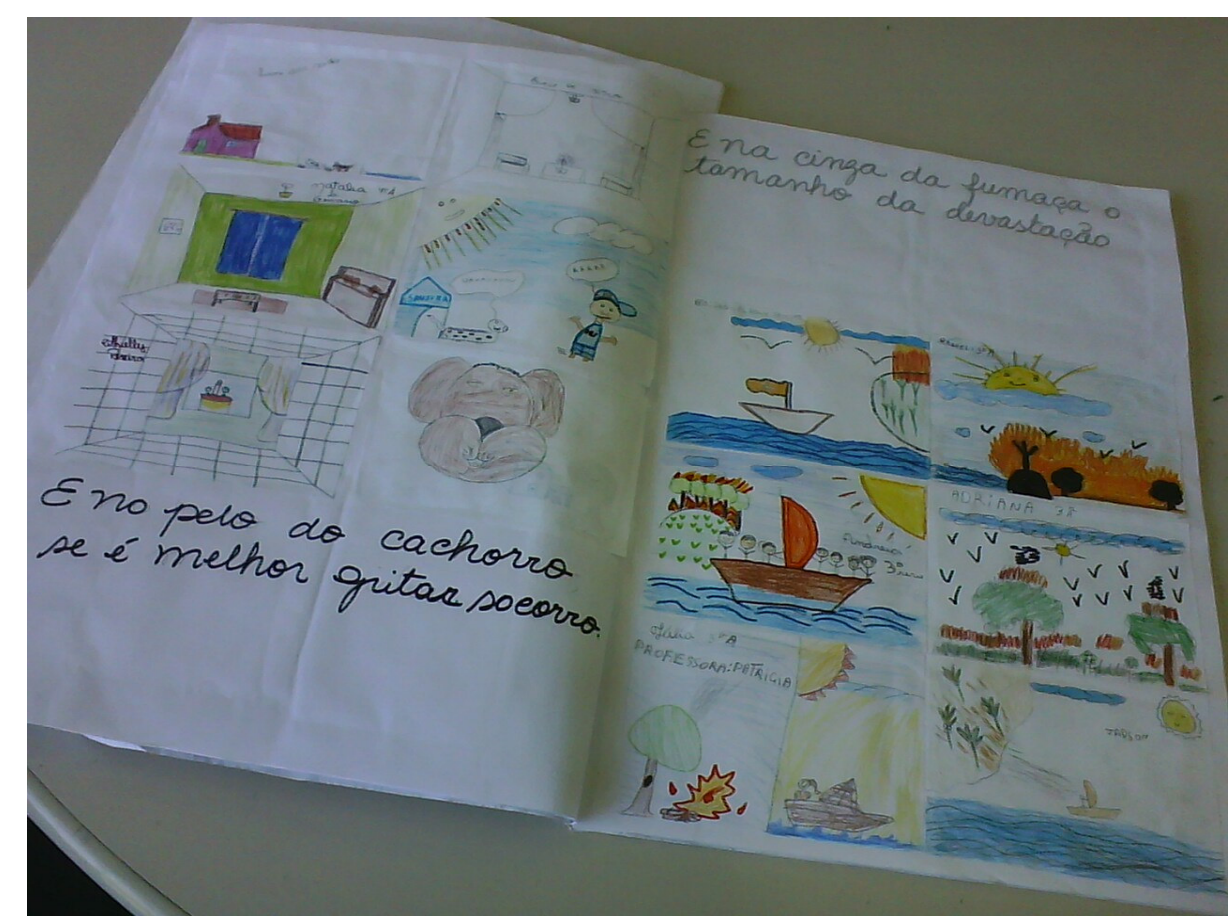

FIGURA 3

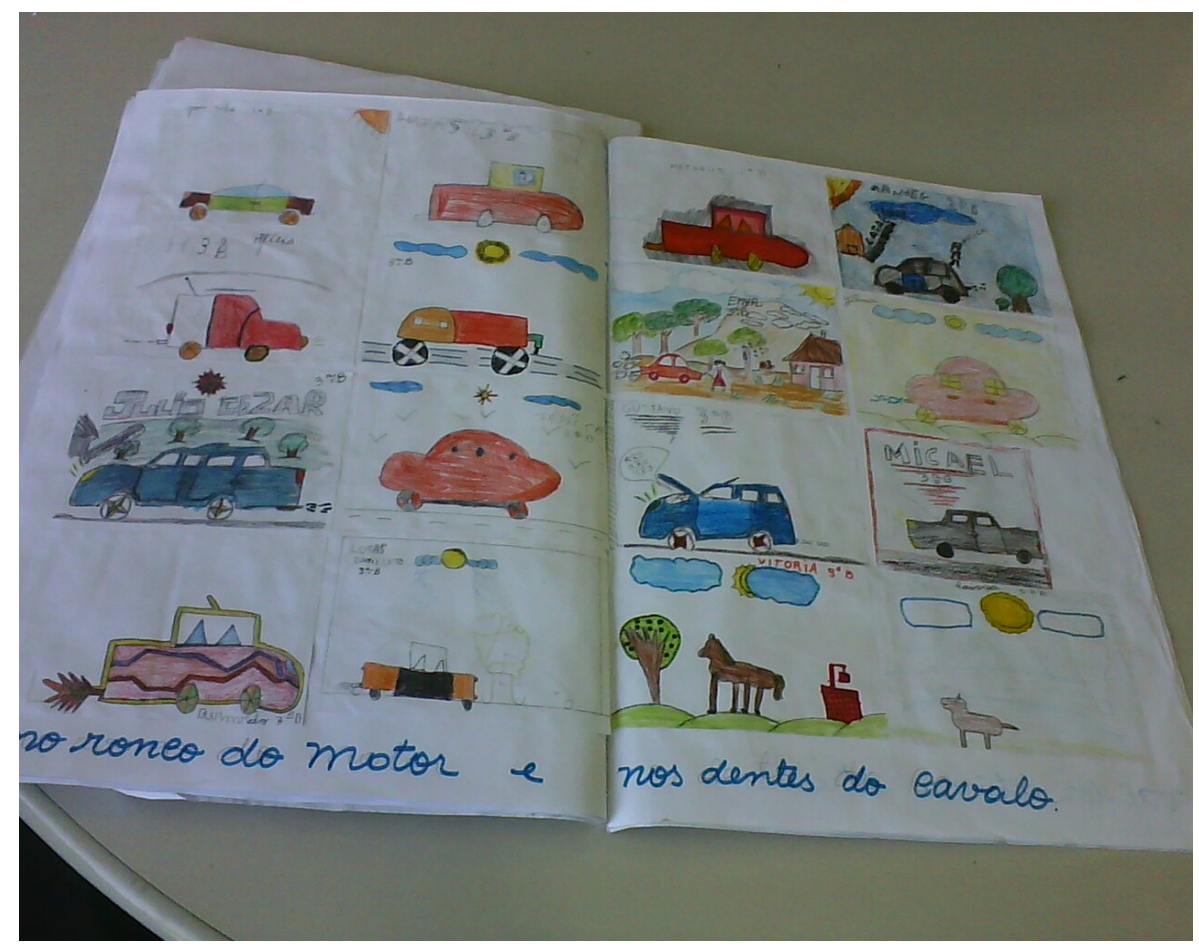

FIGURA 4

Outro objetivo das atividades de leitura é provocar o aluno a olhar para si mesmo, como foi possível experimentar com o trabalho realizado a partir do livro Diversidade de Tatiana Belinky (1999). O livro foi transcrito e ilustrado em cartazes e apresentado aos alunos. O texto traz a beleza da diversidade, afirmando que cada um é especial, não importa 
idade, sexo, cor, etc. Depois, cada criança foi convidada a desenhar o próprio rosto. Todos os "auto-retratos" foram reunidos em um livro artesanal que foi chamado de "Livro da Diversidade" (FIG. 5 e 6). Ou seja, por meio da leitura discutiu-se a diversidade, o respeito às diferenças e a autoestima, já que cada um contribuiu com sua beleza para o livro. Essa atividade é realizada sempre que uma nova turma ingressa no Ensino Fundamental. O livro, dessa forma, permanece em aberto, sempre esperando novos rostos.

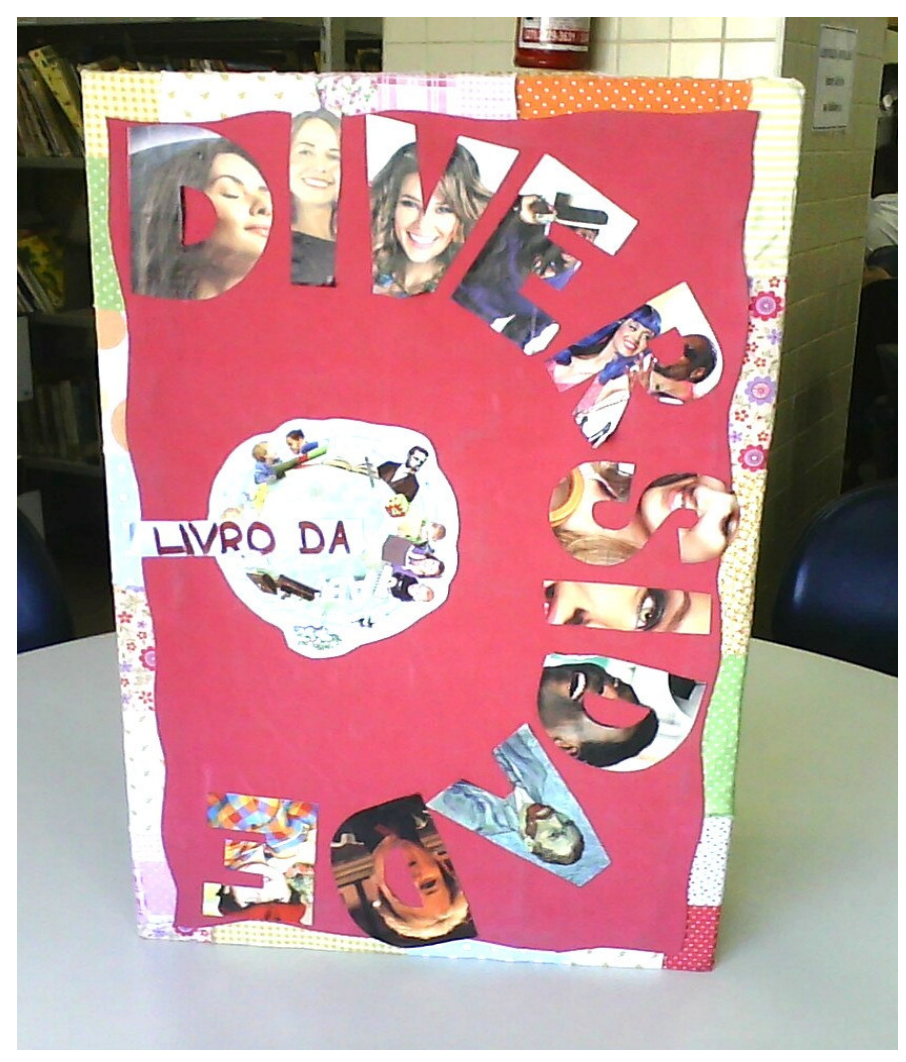

FIGURA 5 


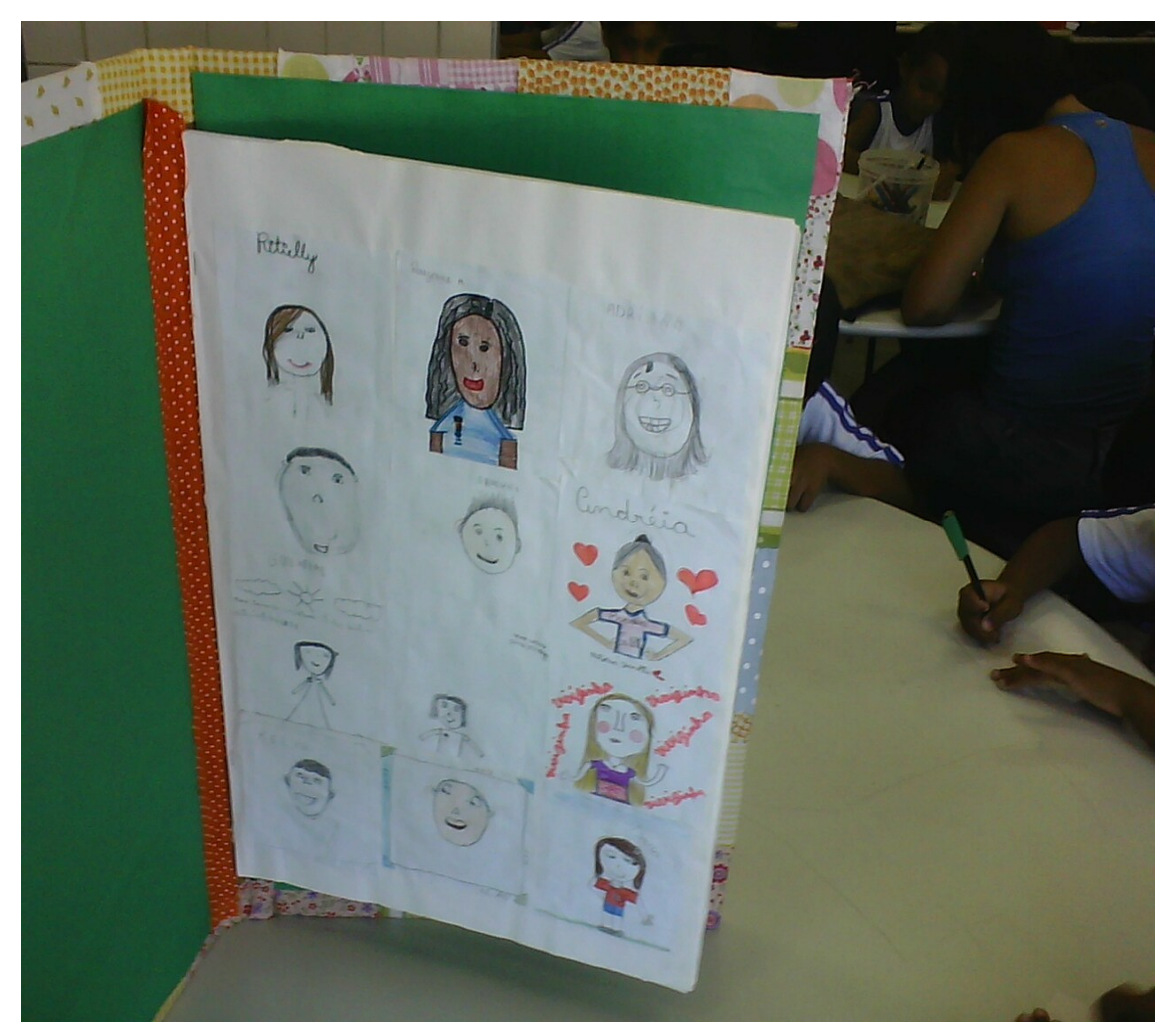

FIGURA 6

A escrita também se faz presente delineando outras atividades e abordagens. O livro Nicolau tinha uma ideia, de Ruth Rocha (1998), mostra a mudança que aconteceu numa comunidade quando Nicolau incentivou todos a compartilharem e trocarem ideias. Ao final, os alunos são convidados a registrar suas ideias, seja através de desenhos, de texto ou das duas modalidades expressivas. Os trabalhos são reunidos no "Livro das Ideias", feito de capa de papelão e com folhas internas em papel cenário branco onde as ideias ficam guardadas e que também permanece aberto para as novas ideias das novas turmas ingressantes (FIG. 7, 8 e 9). 


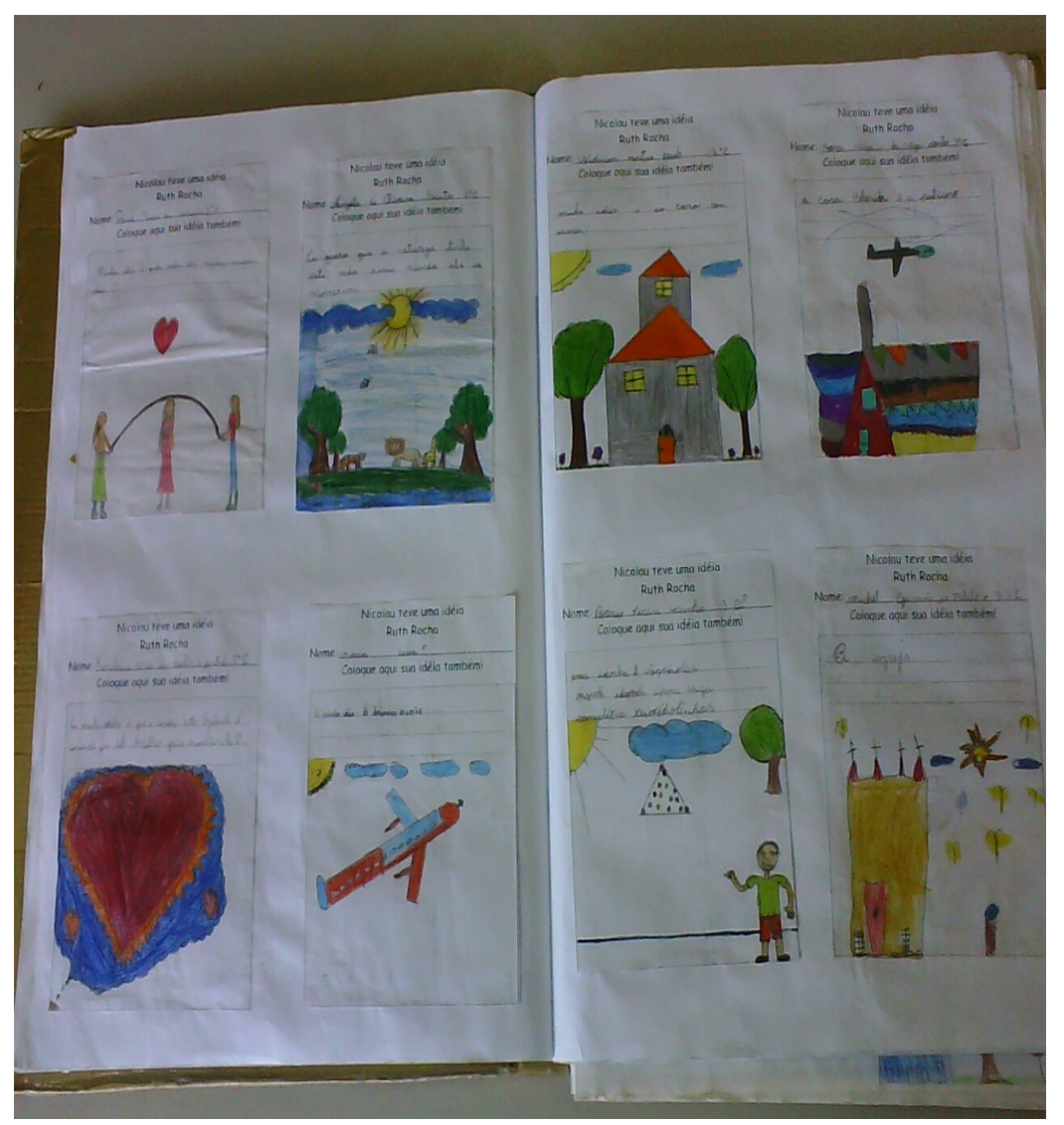

FIGURA 7

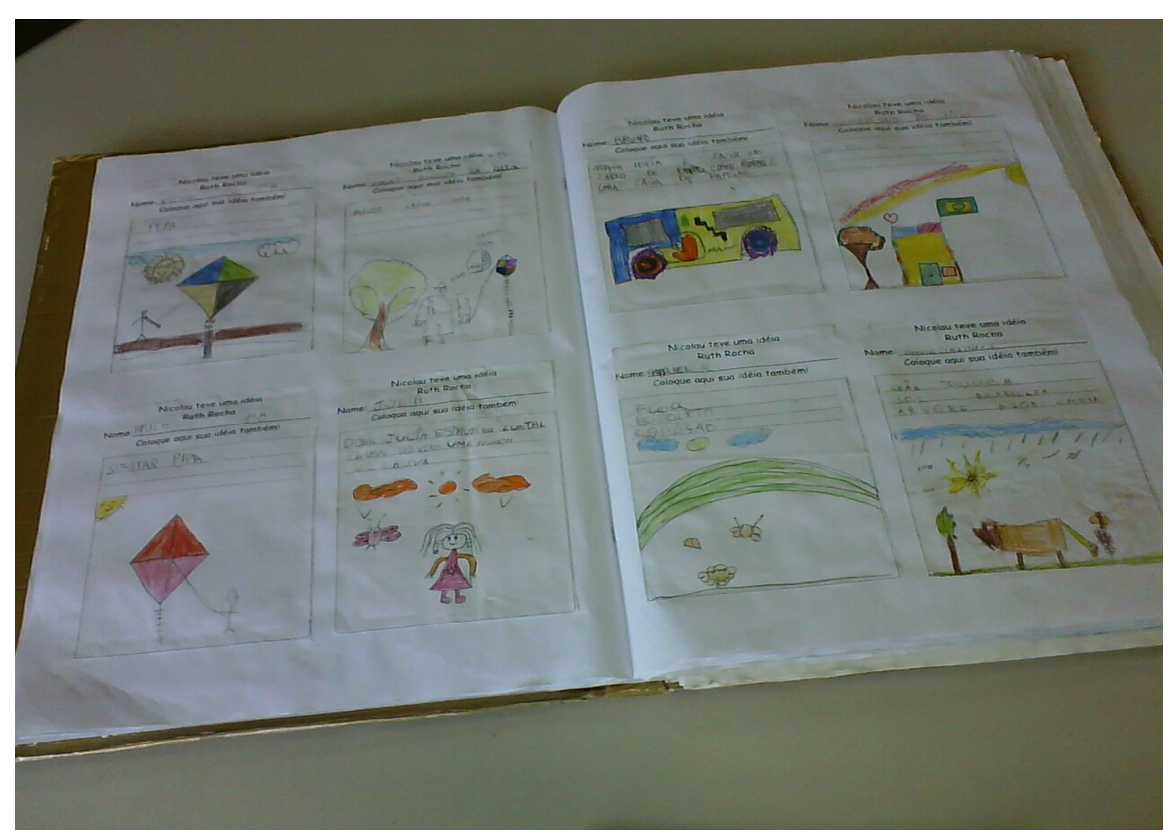

FIGURA 8

Bibl. Esc. em Rev., Ribeirão Preto, v. 2, n. 1, p. 106-124, 2013. 


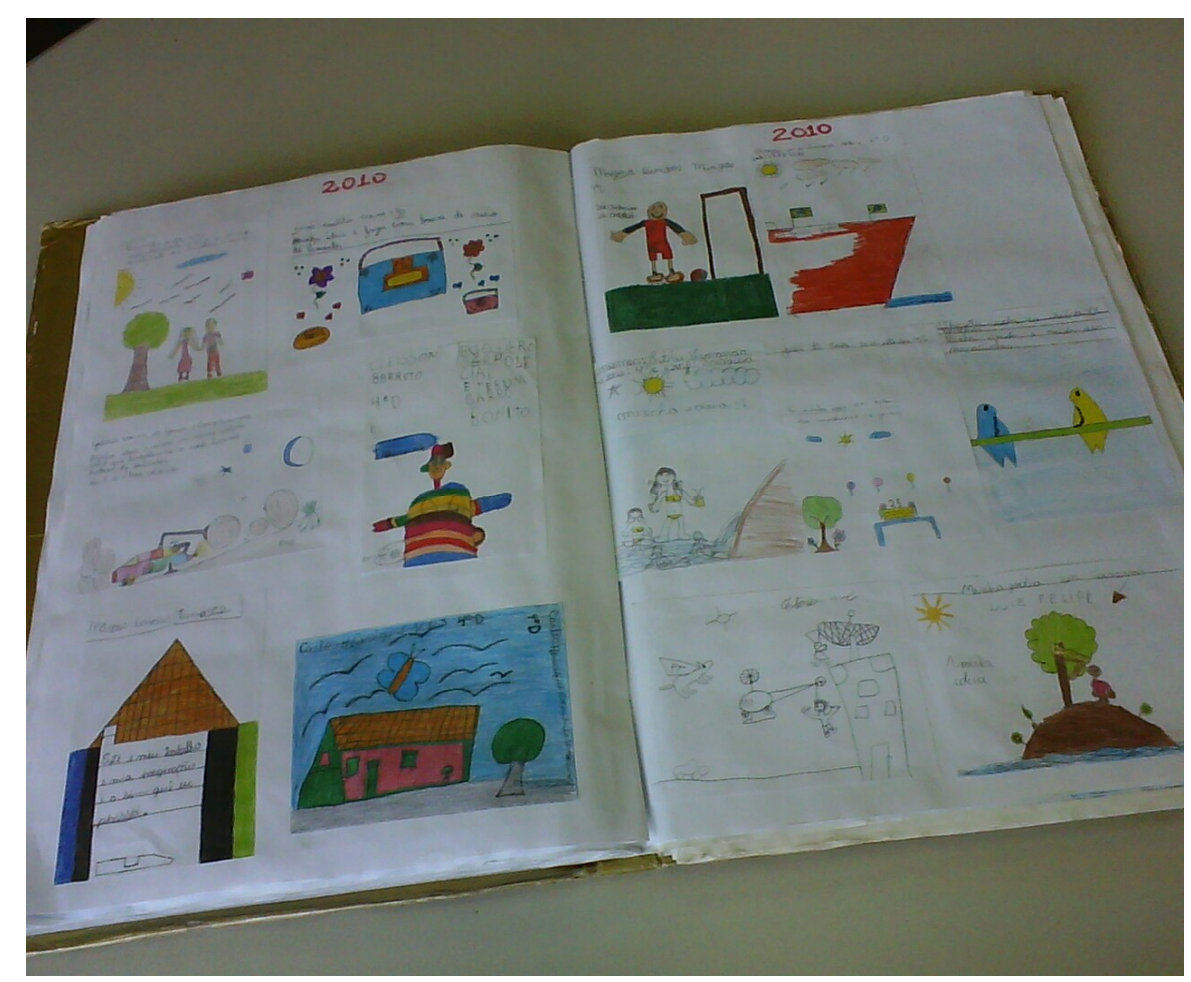

FIGURA 9

A música é o grande "trunfo" para atrair a atenção das crianças para a leitura, principalmente para a leitura de poemas. A atividade é feita de uma forma muito simples: a letra do poema é escrita em um cartaz e lida com ritmo ao som de uma base de hip-hop ou rap (baixada da internet) ou dos acordes de um violão. A batida cadenciada, misturada ao poema deixam os alunos encantados e os incentivam a ler corretamente, pois de outro modo as palavras não se encaixam na música.

O livro Dezenove Poemas Desengonçados, de Ricardo Azevedo (1998) também traz diversos poemas que podem ser trabalhados em forma de rap (o significado da sigla em inglês já é bem sugestivo: ritmo e poesia). O poema que faz mais sucesso entre os alunos é A vaca e $o$ boi, um texto divertido que conta a história de uma vaca que tinha ciúme de um boi solteiro...

A vaca e o boi

A vaca falou pro boi

- Onde foi que você foi?

$\mathrm{O}$ boi mugiu sorridente

que estava com dor de dente.

A vaca disse: - é mentira!

(e quase perdeu a linha). 


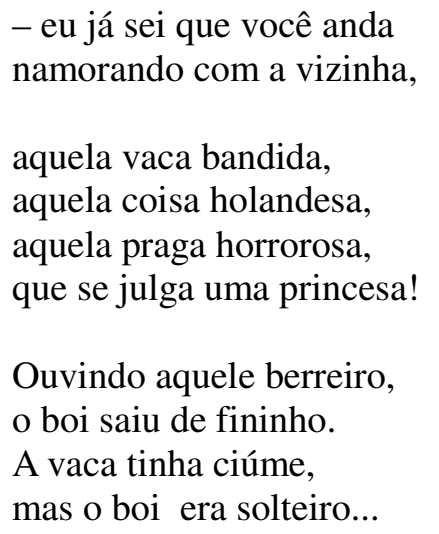

Em suas visitas à biblioteca escolar é frequente os alunos pedirem para cantar o "Rap da Vaca”. Sua participação é ativa, no sentido de surgirem novos arranjos, de imitarem o mugido da vaca e de criarem movimentos, expressões, gestos, etc.

Mesmo quando as crianças ainda não sabem ler, mas já reconhecem algumas letras ou sílabas, o cartaz com o poema transcrito é, em si, um estímulo à leitura. As bases de rap são baixadas da internet, depois exibimos a gravação e o ritmo envolvente contagia a todos. $\mathrm{O}$ importante é destacar o ritmo, lembrando que é preciso falar corretamente todas as sílabas para "encaixar" o poema no ritmo. Essa atividade é realizada todas as vezes que os alunos vão à biblioteca.

Com isso, poemas de vários autores são “cantados" pelos alunos, que leem poesia brincando. Essa prática já rendeu ótimas apresentações na escola. São organizados e ensaiados na biblioteca para apresentar para toda a escola, e até fora dela, em algumas ocasiões. O fato é que misturar poesia e música contribui para que os alunos se empenhem e desenvolvam o gosto pela leitura a partir de ritmos e modos de leitura por eles vivenciados e apreciados.

As atividades com músicas são muito envolventes e já houve a oportunidade de ver crianças cantando as canções e poesias antes mesmo de ensiná-las, pois já haviam aprendido com os irmãos mais velhos que estudam na escola.

A poesia não é trabalhada somente com música; poesias são lidas sem acompanhamento musical para os alunos para que eles comecem a apreciar o texto poético. Sempre usa-se o recurso de interpretação por meio de desenhos que depois são reunidos em livros artesanais, de forma a perpetuar aquele momento de apreciação de poesia, como foi feito com o poema Cheiro de terra, de Ronald de Carvalho, citado por André Neves no livro A caligrafia de Dona Sofia (NEVES, 2001). 


\section{Cheiro de terra}

Há versos que são como um jardim depois da chuva:

deixam em nós a sensação de água caindo, caindo em bolhas trêmulas da ponta das folhas, escorrendo da pele macia das pétalas, pingando nos galhos lavados, gota a gota, pingando no ar...

Versos que cheiram a terra molhada, versos que são como jardim depois da chuva... (CARVALHO apud NEVES, 2001, p. 24).

O poema foi lido para os alunos que desenharam suas interpretações (FIG. 10, 11 e 12):

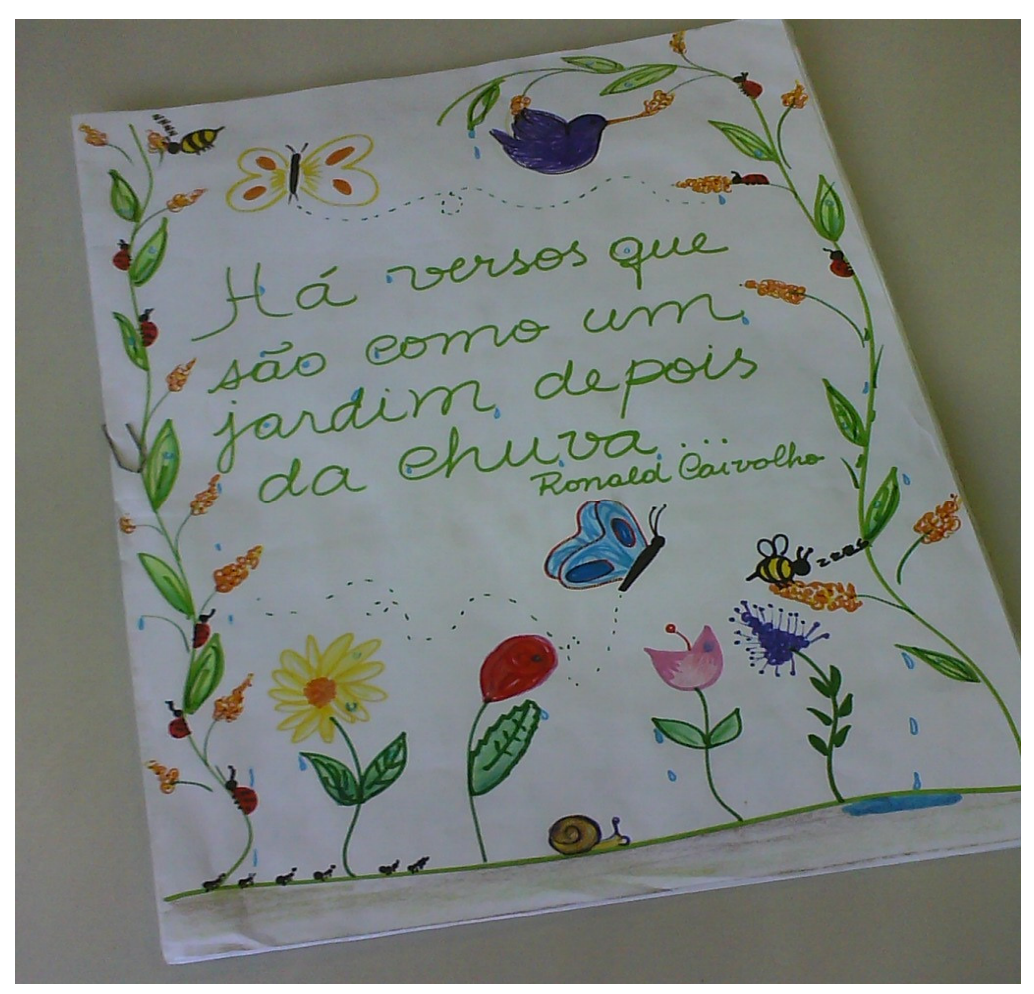

FIGURA 10 


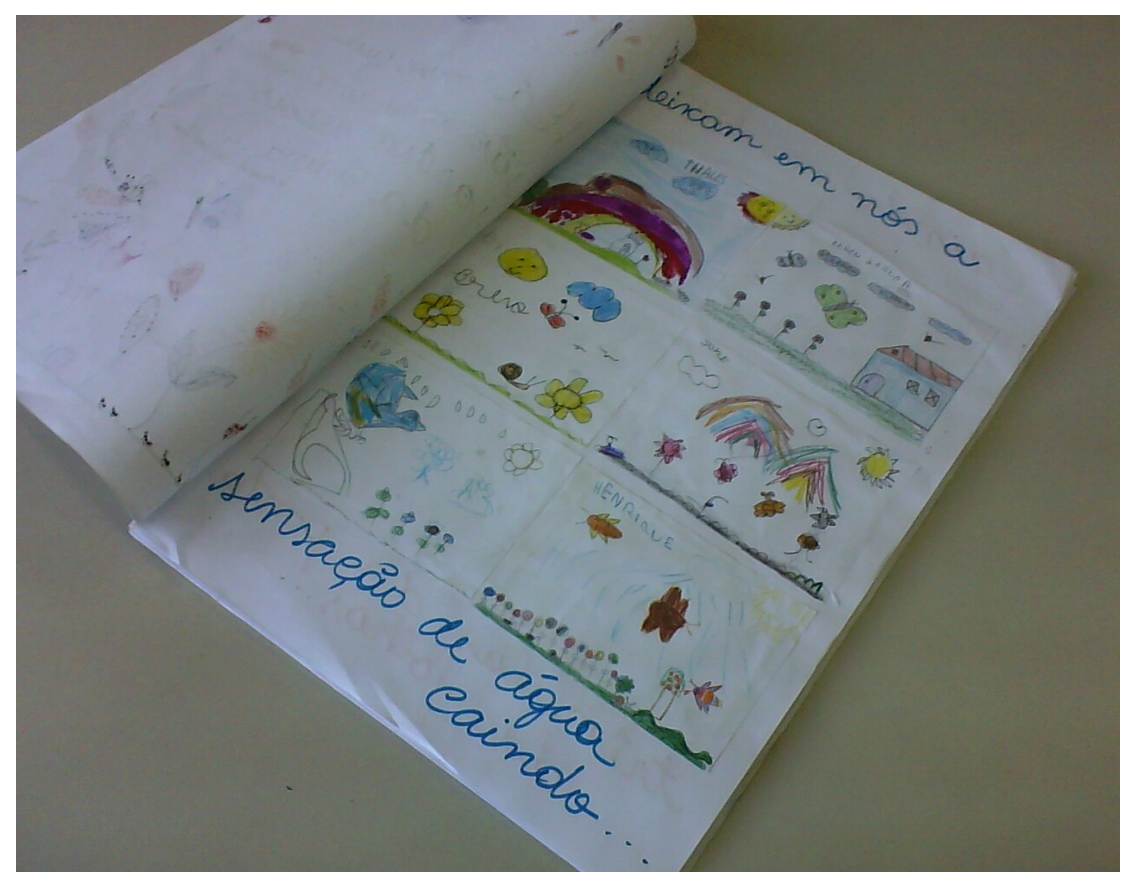

FIGURA 11

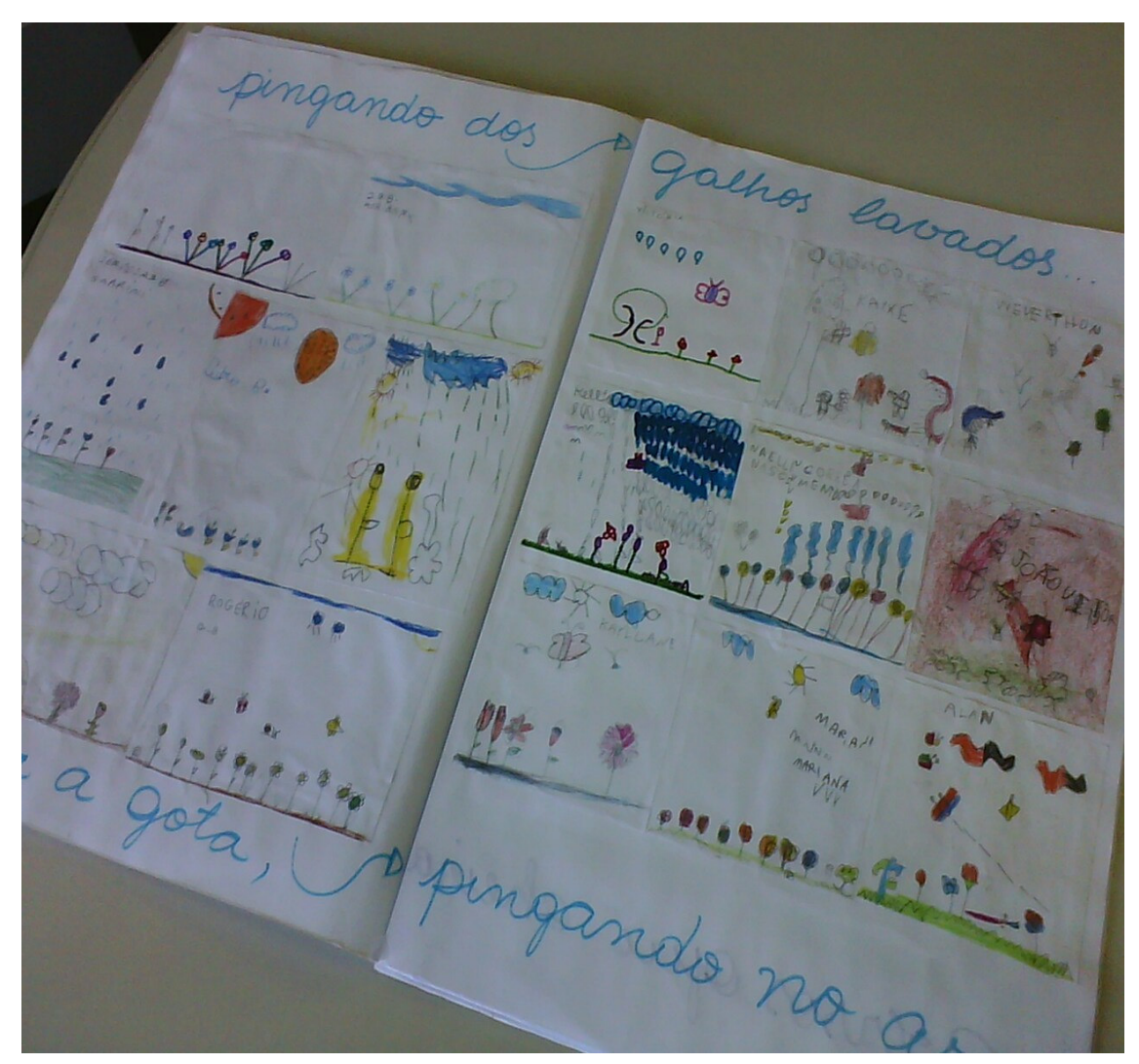

FIGURA 12

A "contação" de histórias também é destaque nas atividades. Em todos os encontros há momentos de leitura de histórias; na maioria das vezes o livro é lido para os alunos, mostrando as ilustrações e procurando apresentar uma entonação que chame atenção com 
vozes e expressões dos personagens. Há histórias que acabam caindo no gosto dos alunos e que, por essa razão, a bibliotecária é levada a contar diversas vezes. O importante é chamar atenção para o livro. Frequentemente, o livro que foi lido para eles, é o primeiro que querem ver, ler e consultar. Depois da leitura em voz alta para a turma eles com frequência pedem: "Marcela, deixa eu ver o livro que você leu?"

Estas e muitas outras atividades realizadas levam a fazer brotar de cada livro, além da própria história contada, valores, emoções, encantamento, e, sobretudo, o prazer da leitura. E isso é bem vindo em qualquer escola que se comprometa em convidar o aluno ao melhor momento da aula: o encantamento de descobrir na leitura um modo de aprender e se divertir.

\section{Resultados obtidos}

Os resultados do trabalho realizado no $\mathrm{ABL}$ não passam por processos de levantamento numérico, quantitativo; na verdade os resultados qualitativos são verificáveis ao se observar as reações dos alunos a cada dia. Por exemplo, se eles leem um poema em ritmo de rap e memorizam o poema, já passam a cantar toda vez que me veem quando se chega à porta da sala de aula, passa-se por eles no pátio. Também é comum pedirem insistentemente para cantá-lo no mesmo instante em que a turma entra na biblioteca escolar para o encontro quinzenal.

Os trabalhos de desenho e escrita que fazem na biblioteca também demonstram que eles compreenderam bem o texto, seja em poesia ou prosa. Certa ocasião, uma aluna com diagnóstico de dificuldades de aprendizagem, participou da atividade realizada a partir do poema Diversidade, acima citada, em que cada aluno tinha que desenhar o próprio rosto. Descobriu-se, maravilhada, o seu notável talento para o desenho. O rosto retratado não parecia exatamente com o dela, mas tinha um detalhamento fantástico, sobretudo do olhar. Há outras crianças que demonstram baixa autoestima ao se retratar nessa atividade como loiras de olhos claros, quando na verdade são negras. Sempre se conversa com elas, diz-se o quanto são bonitas e que devem se retratar como são.

Essas experiências têm demonstrado que os alunos podem ampliar a leitura para além de "decifrar palavras", como diz Ricardo Azevedo, pois desse modo, como ele mesmo afirma, pode-se até surpreender. 


\section{Algumas dificuldades encontradas}

A principal dificuldade hoje encontrada é a falta de pessoal. Em vários períodos assumiu-se sozinha todas as atividades da biblioteca, o que dificulta o andamento dos projetos e a própria dinâmica da biblioteca, e também faz que com que as funções técnicas fiquem comprometidas. Outra questão importante é o sistema de automação que ainda não foi implantado. Atualmente a Prefeitura de Vitória está em processo de automação das bibliotecas escolares, mas o ABL ainda não foi contemplado com a instalação do sistema, o que favorecerá uma ação mais efetiva a partir das estatísticas e de dados mais elaborados, além do melhor aproveitamento do acervo.

\section{Conclusão}

Apresentar o livro e a leitura às crianças é um desafio, alguns obstáculos precisam ser vencidos. O bibliotecário precisa assumir o seu papel de mediador, direcionando as suas atividades para os interesses dos alunos, ser criativo e estar disposto a interagir com eles. Caso não tenha aptidão para atividades diferenciadas, é necessário, no mínimo, que se predisponha a ler em voz alta para eles.

Retornando às palavras do acróstico: SaBer, Imaginação, Brincadeira, Leitura, MúsIca, Poesia, CulTura, ArtE, Cidadania, InformAção (FIG. 13), segue-se acreditando no significado dessas palavras e acreditando que a biblioteca tem um papel fundamental na escola. 


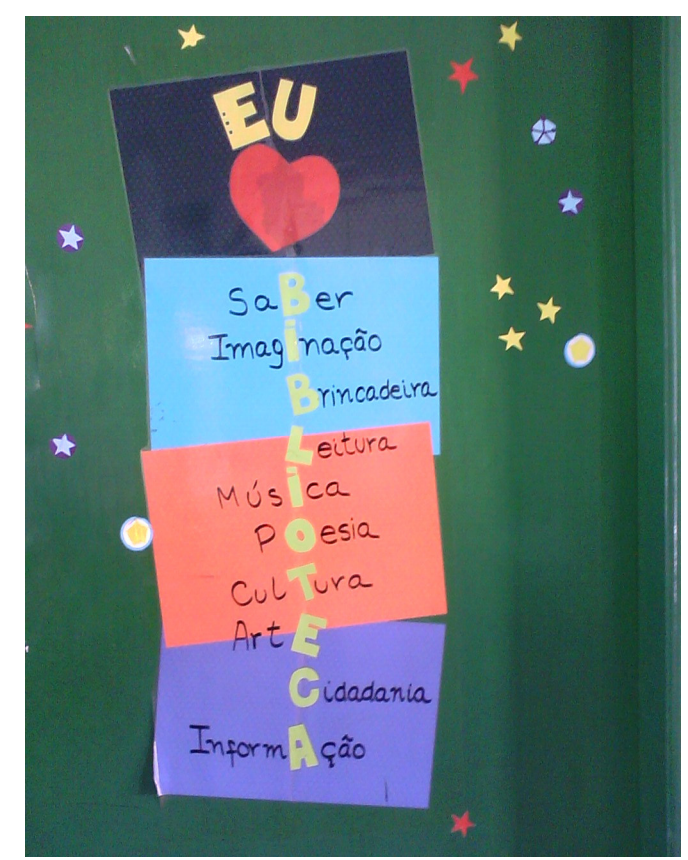

FIGURA 13

Colocar em prática a função educativa da biblioteca exige esforço de todos na escola. Ao bibliotecário cabe compreender seu papel de educador e exercê-lo com competência e criatividade. Além disso, ele precisa desenvolver e demonstrar seu gosto pela leitura, seu entusiasmo diante dos livros, seu encantamento provindo da leitura para, desse modo, envolver o leitor. Tudo isso exige contato com os alunos, não há como fugir das atividades pedagógicas nem de uma pequena "bagunça" na biblioteca. Inovar por meio de atividades com música, teatro, filmes, artes plásticas, dentre outros recursos e meios, é muito importante para que os alunos encontrem prazer na leitura, tenham curiosidade de ver aquele livro que foi lido, cantado ou encenado. Enfim, um pouco de encantamento, com criatividade e paciência, pode fazer da biblioteca um espaço vivo, acolhedor, agradável e dinâmico que realmente cumpra seu papel.

Na participação no Fórum Brasileiro de Bibliotecas Escolares espera-se poder absorver o máximo de informações, compartilhar ideias, aproveitar os momentos com profissionais mais experientes e desse modo enriquecer a prática com tudo o que terá oportunidade de ver, ouvir e sentir. 


\section{Referências}

ANJOS, Andreia Couto. A criação de práticas de incentivo à leitura: o papel do bibliotecário escolar na formação de leitores. 2009. Trabalho de Conclusão de Curso (Bacharelado em Biblioteconomia) - Universidade Federal do Espírito Santo, Vitória, 2009.

AZEVEDO, Ricardo. Dezenove poemas desengonçados. São Paulo: Ática, 1998.

BELINKY, Tatiana. Diversidade. São Paulo: Quinteto Editorial, 1999.

CAMPELLO, Bernadete Santos. Letramento informacional: função educativa do bibliotecário na escola. Belo Horizonte: Autêntica, 2009.

CAMPELLO, Bernadete Santos. Perspectivas de letramento informacional no Brasil: práticas educativas de bibliotecários em escolas do ensino básico. Encontros Bibli: R. Eletr.

Bibliotecon. Ci. Inf., Florianópolis, v. 15, n. 29, p. 184-208, 2010. Disponível em: <http://www.periodicos.ufsc.br/index.php/eb/article/view/1518-2924.2010v15n29p184>. Acesso em: 05 jun. 2013.

CORREA, Elisa Cristina Delfini, et al. Bibliotecário escolar: um educador? Revista ACB: Biblioteconomia em Santa Catarina, Florianópolis, v. 7, n. 1, p. 107-123, 2002. Disponível em: <http://revista.acbsc.org.br/racb/article/view/379/458>. Acesso em 12 jun. 2013.

IFLA. Manifesto IFLA/UNESCO para biblioteca escolar. Tradução Neusa Dias Macedo. São Paulo, 2000.

IFLA. Diretrizes da IFLA/UNESCO para bibliotecas escolares. Tradução de Maria José Vitorino. São Paulo, 2006.

NEVES, André. A caligrafia de Dona Sofia. São Paulo: Paulinas, 2001.

NEVES, Iara Conceição Bitencourt. Ler e escrever na biblioteca. In: NEVES, Iara Conceição Bitencourt et al. (Org.). Ler e escrever: compromisso de todas as áreas. Porto Alegre: Ed. UFRGS, 2004.

ROCHA, Ruth. Nicolau tinha uma ideia. São Paulo: Quinteto Editorial, 1998. 